\title{
The improvement of the technique for determining technical condition of repair and maintenance equipment
}

\author{
Denis Molochnikov ${ }^{1, *}$, Rustam Khalimov ${ }^{1}$, Ilnar Gayaziev ${ }^{2}$, Dmitry Rudoy ${ }^{3}$, and \\ Anastasiya Olshevskaya ${ }^{3}$ \\ ${ }^{1}$ Federal State Budgetary Educational Institution of Higher Education "Ulyanovsk State Agrarian \\ University named after P.A. Stolypin", 432017, Ulyanovsk, boulevard Novy Venets, 1, Russia. \\ ${ }^{2}$ Federal State Budgetary Educational Institution of Higher Education " Kazan State Agrarian \\ University», 420015, Republic of Tatarstan, Kazan, ul. Karla Marksa 65 \\ ${ }^{3}$ Don State Technical University, 344003, Gagarin sq., 1, Rostov-on-Don, Russia
}

\begin{abstract}
The authors of the paper have established the dependence of the technological system condition of repair equipment during its operation on the repair quality of machine parts. The technique has been proposed to determine the machining quality of the parts repaired. It is based on an integrated method for calculating and determining technical condition of typical repair equipment in view of the proposed integral criterion for assessing its vibration resistance.
\end{abstract}

\section{Introduction}

Modern agricultural machinery is very high-tech equipment, repair of which with a high professional level and quality is sure to be a laborious and difficult task. The quality of machinery repairs is determined by the quality of repair equipment, for example, when restoring various parts [1-3]. It is determined on the basis of various indicators, including: vibration resistance and output, precision, the quality of performed repair operations. However, they are assessed as a set of dynamic processes, due to the increased requirements for the used parts of modern tractors and farm vehicles [4-5]. This thereby emphasizes the necessity to improve the performance of repair equipment and achieve optimal dynamic characteristics.

In connection with the abovementioned, the objective is to create new repair equipment or modernize existing one, including precision of machines that correspond to foreign ones in their technical level. Solving such a problem requires further study and research into the field of machine tool dynamics, methods of calculating and assessing the dynamic state, and subsequent optimization of dynamic characteristics for a number of limiting factors. It also requires the development of reliable calculation and experimental methods that allow consumers to give an objective assessment of the technical level of metal-cutting machines

\footnotetext{
* Corresponding author: denmol@yandex.ru
} 
of a similar purpose, but different in engineering and technical performance which have certain design features.

Conversely, the modern trend in the development of machine tools, due to the continuously increasing requirements for them, is accompanied by a constant increase in the rotational speed of the main movement up to $4000-6000 \mathrm{rpm}$, the feed of the working and idle speed up to $0.5-3.0$ and $10-20 \mathrm{~m} / \mathrm{min}$, respectively, by reducing the acceleration and deceleration time of the working bodies to $0.02 \mathrm{~s}$ with simultaneously high requirements for precision and roughness of the surfaces of the workpieces, etc. In this regard, the issues of further study of vibrations in machines also acquire special importance. Based on the foregoing, the paper is devoted to the development of technological solutions in the process of creating a range of precision metal-cutting machines, in terms of their technical level equal to foreign machines, as well as techniques of their calculation and quality research, taking into account, for example, the specifics of the ratio of the limiting vibration characteristics when cutting in the working space [25-26].

The quality of processing parts of agricultural machinery is determined on the basis of various indicators, including: vibration resistance and output, precision, quality of repair operations performed. However, they are assessed as a set of dynamic processes, due to the increased requirements for the used parts of modern agricultural machinery [4 - 5]. This thereby emphasizes the need to improve the performance of repair equipment and achieve their optimal dynamic characteristics.

\section{Materials and methods}

To achieve high quality of repairing machinery, the system of repair equipment can be considered as a single integral criterion which can be used for the synthesis and optimization of technological systems by comparing output parameters, as well as assessing the technical level of repair equipment [6].

A key feature of the considered technique [7 - 8] is its application in a complex reflecting very different dynamic phenomena in technological systems of the equipment used, for example boring machines, and high requirements for dynamic processes (through a very wide range of changes in the parameters of the dynamic system of repair equipment cutting speed, tool feed, dimensions, weight, configuration, materials, requirements for precision of parts, etc.).

Taking account of the inconsistency and mutually exclusive nature of the considered initial values of the dynamic quality of equipment, such as precision and output, this method provides:

- determination of the ultimate (integral) stability in the case of power conversion, which is used to calculate the output when rough machining a workpiece;

- assessment of precision during finish machining.

Let us consider the first condition, when the operability of the dynamic technological system of the boring machine is limited by its vibration resistance, and the rigidity of a part is taken into account in view of the repair work to be done [8]. The output is quantified in the following order. First, the relative dimensions of the part in the plane of its machining and the integral dynamic characteristics of the equipment are determined to ensure vibration resistance which consists of a number of restrictions that together act in the technological system that determine the curve of the stable cutting boundary $t_{\text {cal }}$. within the standard length of the workpiece:

$$
t_{b}[8] ; t_{N}=\frac{6120\left(N_{i z m}-N_{h . h .}\right)}{K_{1} \cdot S^{0,75} \cdot V}, t_{M}=\frac{2000 M}{K_{1} \cdot S^{0,75} \cdot D},
$$


Then, after determining the numerical value of the limiting integral criterion of vibration resistance $t_{\text {integr }}$ for cutting with the use of this curve in the given system of coordinates, the permissible (specific) metal removal rate is calculated using the expression:

$$
Q=t_{\text {integr }} \cdot S \cdot V\left(1-\frac{t_{\text {integr }}}{D}\right)
$$

where: $t_{\text {integr }}$ is the limiting integral characteristics of vibration resistance (integral depth of cutting the walls of an engine block) obtained within the whole working space of the machine, $\mathrm{mm}$;

$\mathrm{S}$ - cutter feed, $\mathrm{mm} / \mathrm{rev}$;

$\mathrm{V}$ - speed of cutting, $\mathrm{m} / \mathrm{min}$;

$\mathrm{D}$ - diameter of the workpiece machined, $\mathrm{mm}$.

Therefore, the maximum removal rate of the removed metal is in direct proportion to the maximum allowable value of the depth of cutting for the considered repair equipment, taking account of the location of the cutter in its working space.[23]

The technical level of metal-cutting equipment is determined with software using such a multifactor indicator as output [7], by calculating the machining cycle time of a conventional component:

$$
T=\frac{V_{c}}{Q}+\frac{L}{S_{b . p .}}+\frac{T_{i} \cdot n}{60}+\frac{T_{d}}{60},
$$

where: $\mathrm{T}$ - the workpiece machining time, min;

$\mathrm{Q}$ - admissible rate of metal removal at maximum permissible machining with the depth of cutting $\mathrm{t}_{\text {integr }}, \mathrm{cm}^{3} / \mathrm{min}$;

$\mathrm{S}_{\text {b.p. }}-$ speed of movements of the cutting tool, $\mathrm{mm} / \mathrm{min}$;

$\mathrm{V}_{\mathrm{c}}-$ volume of chipping for a machining cycle, $\mathrm{cm}^{3}$;

$\mathrm{L}$ - total length of movements, $\mathrm{mm}$;

$\mathrm{T}_{\mathrm{i}}-$ time of the tool position change, $\mathrm{s}$;

n- number of tools of repair equipment;

$\mathrm{T}_{\mathrm{d}}$ - time of the tool position change, $\mathrm{s}$.

The limit values of dynamic stability can be determined both by calculating all limit values, and by calculating the test results of design models and their experimental use. This allows one to take account of the following factors [8]:

- design characteristics of the main assembly units, control models of repair equipment, their location, drive structure, spindle torque and effective cutting characteristics;

- the possibility of obtaining an objectively differentiated assessment of the dynamic state of equipment through calculation or calculation with the experimental use of digital technologies; [24]

- changing the position of the tool in the working space of the repair equipment, material and geometry of the tool, material of parts, flexibility of the technological system.

Another evaluative parameter, which is used to assess the repair effects, is the roughness of the machined surface during finish machining [9-14].

The stable formation of the maximum surface quality of the part during machining with the supply of directed regular surface microreliefs depends on the problem: the choice of a number of limiting factors and the acceptance of boundary conditions.

The influence of the cutter feed on the surface roughness of the workpiece during turning can be determined using the Chebyshev formula: 


$$
R_{z}=\frac{S^{2}}{8 \cdot r} \cdot 1000
$$

where: $\mathrm{R}_{\mathrm{z}}$ - average peak to valley height, $\mathrm{mcm} ; \mathrm{R}_{\mathrm{z}}=4 \mathrm{Ra}$; $\mathrm{S}-$ feed rate, $\mathrm{mm} / \mathrm{rev}$; $\mathrm{r}-$ radius with the cutter tip, $\mathrm{mm}$.

To obtain optimal surface finish, the tool feed during finish machining is set in the range from 0,01 to $0,2 \mathrm{~mm} / \mathrm{rev}$. In this case, additional calculations of the cutter feed should be carried out according to the refined formula, determined by the roughness of the workpiece:

$$
S_{\text {rough }} \leq \frac{k_{0} \cdot R_{a}^{k_{1}} \cdot V^{k_{2}} \cdot r^{k_{3}} H B^{k_{4}}}{t^{k_{5}} \cdot \varphi^{k_{6}} \cdot \varphi_{1}^{k_{7}}}
$$

where: $\mathrm{k}_{0}, \mathrm{k}_{1}, \ldots \mathrm{k}_{7}$ are the coefficients characterizing machined and tool material (they are given in manuals for different types of machined and instrumental materials);

$\mathrm{t}$ - depth of cutting $(0,05-0,1 \mathrm{~mm})$;

$\mathrm{R}_{\mathrm{a}}$ - arithmetic mean deviation of the surface roughness;

$\mathrm{r}-$ nose radius;

$\varphi$ and $\varphi_{1}-$ main and auxiliary angles of the tool respectively;

$\mathrm{BH}-$ Brinell hardness of the material of the repaired part.

From formula (5) and the established nominal mode when finishing medium-carbon steels and cast irons, for example, by turning with VK8 cutters, the value of the parameter Ra can be determined by formula (6):

$$
R_{a}=0,85 \frac{t^{0,31} \cdot S^{0,58} \cdot \varphi^{0,4} \cdot \varphi_{1}^{0,4}}{V^{0,06} \cdot r^{0,66} \cdot H B^{0,05}}
$$

Additionally, the calculation of the tool feed is made taking account of the permissible rigidity and precision of the part:

$$
S_{r i g} \leq X p_{z} \sqrt{\frac{\varepsilon^{\prime} J E f^{1}}{1,1 C_{p z} \cdot l^{3} \cdot t^{u r_{z}}}}
$$

where: $\mathrm{f}$ - change of the geometrical straightness of the part when machining;

1 - the distance between the bases of the equipment or the overhang of the part (when it is c lamped only in the chuck);

$\mathrm{J}=$ moment of inertia of the section of the part (for round solid parts);

$\mathrm{E}$ - elastic modulus of the machined part material;

$\mathrm{J}=0,05 \mathrm{~d}$, where $\mathrm{d}$-circular diameter of the machined surface;

$\dot{\varepsilon}$ - stiffness coefficient, depending on the method of clamping the part on the machine: $\dot{\varepsilon}=3$ (when holding in the chuck), $\dot{\varepsilon}=48$ (when holding in centers),

$\dot{\varepsilon}=96$ (chuck clamping with the use of boring machine table).

When finishing, the machining speed of the part is determined by the known conditions of cutting taking account of the required depth of cutting and the feed rate of the tool. There is no chip formation at the cutting edge of the cutter during machining. One can also apply the empirical equation [15-19] to find the Ra parameter for conditions of finishing machining:

$$
R_{a}=K \frac{S^{k_{1}}\left(90^{0}+\gamma\right)^{k_{4}}}{r^{k_{2}} \cdot V^{k_{3}}}
$$


After setting the optimum modes of cutting for finish machining: $\mathrm{V}, \mathrm{S}, \mathrm{t}$, assessing the rigidity of the technological system it is necessary to determine specific output of repair equipment (machining time $1 \mathrm{dm}^{2}=10000 \mathrm{~mm}^{2}$ of the surface area of a basic component) using the formula:

$$
T_{M}=\frac{10}{V S}
$$

It is known from the theory of cutting that:

$$
V=\frac{C_{V}}{t^{x} \cdot S^{y}}
$$

Therefore, substituting values (10) in formula (9), we obtain:

$$
T_{M}=\frac{10 t^{x} \cdot S^{y}}{C_{V} \cdot S}=\frac{10 t^{x}}{C_{V} \cdot S^{(1-y)}}
$$

The rigidity of the technological system is determined:

$$
j=K_{y} \cdot C_{p} \cdot S^{0,75} \cdot \frac{\Delta_{3}}{\Delta_{\partial}}
$$

From here it follows:

$$
S^{0,75}=j \frac{1}{K_{y} \cdot C_{p}} \cdot \frac{\Delta_{d}}{\Delta_{3}} \text { or } \quad S=\left(j \frac{1}{K_{y} \cdot C_{p}} \cdot \frac{\Delta_{d}}{\Delta_{3}}\right)^{4 / 3},
$$

where: $\Delta_{\mathrm{d}}-$ geometrical shape error of a part after its manufacturing; $\Delta_{\mathrm{z}}$ - workpiece error before its machining.

As a result, we get the expression:

$$
T_{M}=\frac{10 t^{x}}{C_{V}}\left(\frac{K_{y} \cdot C_{p} \cdot \Delta_{3}}{j \Delta_{\partial}}\right)^{\frac{4}{3}(1-y)}
$$

When finishing the exponent of power $4 / 3(1-y)=1$, therefore it is expedient to use the formula below when calculating the output:

$$
T_{M}=\frac{10 t^{x}}{C_{V}}\left(\frac{K_{y} \cdot C_{p} \cdot \Delta_{3}}{j \Delta_{\partial}}\right)
$$

\section{Results and their discussion}

These dependences make it possible to determine the specified surface quality of the workpiece and to determine the parameters of the repair technological process and the geometry of the cutting tool at the set values of the surface quality.

When repairing a part, primary spontaneous vibrations in the technological system are transformed into secondary (regenerative) vibrations which significantly worsens the quality indicators of the technological process of repairing. Regenerative spontaneous 
oscillations in a closed technological system are the result of defects that determine its roughness on the surface of the workpiece machined, obtained from the previous rough pass of the tool. To obtain the optimal values of the estimated surface quality parameter during the study, various technical solutions have been developed that make it possible, for example, in the simulation mode, to control the vibration level of the technical system of repair equipment, and to provide automatic adjustment of critical machine units during the time of its direct work in accordance with the surface quality. The technical solutions offered throughout the finishing process in the technological system support dynamic fixed self-regulation, which allows the system to establish internal resonance and provide higher repair precision [19-22].

Thus, the indicators of reliability and durability of the considered repair equipment are set during their direct testing, for example, by information technology products which play an important role in predicting changes in the output standardized parameter of repair equipment.

\section{Conclusion}

The dependence of the technological system condition of repair equipment during its operation on the quality of repairing machine parts has been established. A method has been proposed for determining the quality of processing repair parts, including the transfer function of the movable friction unit along the sliding guides of the metal-cutting machine under conditions of semi-fluid (mixed) friction in the form of an equivalent oscillatory link. It is based on an integrated method for calculating and determining technical condition of typical repair equipment based on the proposed integral criterion for assessing its vibration resistance. The transfer functions of the machine support system for various design versions have been determined in view of theoretical developments and experimental data. The proposed complex method for calculating and determining the technical condition of typical repair equipment will make it possible to work out new design solutions and re-equip the existing machine fleet of maintenance enterprises in the agro-industrial complex.

\section{References}

1. S. I. Kambulov, I. V. Bozhko, A. V. Olshevskaya, MATEC Web of Conferences, 224, 05022 (2018) https://doi.org/10.1051/matecconf/201822405022

2. Yu. A. Ivanov, V. I. Pakhomov, S. I. Kambulov, D. V. Rudoi, (ICMTMTE 2018) electronic edition. Cep. MATEC Web of Conferences, 224, 05023 (2018) https://doi.org/10.1051/matecconf/201822405023

3. A. Altybayev, A. Zhanbyrbayev, B. Meskhi, D. Rudoy, A. Olshevskaya, A. Prohorova, E3S Web of Conferences, 135, 01078 (2019) https://doi.org/10.1051/e3sconf/201913501078

4. B. Meskhi, B. Golev, V. Efros, D. Rudoy, A. Olshevskaya, V. Zhurba, Y. Chayka, E3S Web of Conferences, 135, $01083 \quad$ (2019) ITESE-2019 https://doi.org/10.1051/e3sconf/201913501083

5. J. Gerber, A. Zavaly, A. Gavrilov, A. Olshevskaya, N. Kiyan, IOP Conf. Series: Earth and Environmental Science, IOP Publishing, 403, 012014 (2019) doi:10.1088/1755$1315 / 403 / 1 / 012014$

6. G. Parkhomenko, S. Kambulov, A. Olshevskaya, A. Babadzhanyan, N. Gucheva, I. Mekhantseva, IOP Conf. Series: Earth and Environmental Science, 403, 012144 (2019) doi:10.1088/1755-1315/403/1/012144 
7. Y. Lachuga, A. Soloviev, A. Matrosov, I. Panfilov, V. Pakhomov, D. Rudoy, IOP Conf. Series: Earth and Environmental Science, IOP Publishing, 403, 012055 (2019) doi:10.1088/1755-1315/403/1/012055

8. E. Zubrilina, I. Markvo, V. Novikov, A. Beskopylny, L. Vysochkina, D. Rudoy, A. Butovchenko, IOP Conf. Series: Earth and Environmental Science, 403, 012063 (2019) IOP Publishing doi:10.1088/1755-1315/403/1/012063

9. A. Khokhlov, A. Khokhlov, D. Marin, D. Molochnikov, I. Gayaziev, International Scientific-Practical Conference "Agriculture and Food Security: Technology, Innovation, Markets, Human Resources” (FIES 2019), 00077 (2020) doi:10.1051/bioconf/20201700077

10. A. Glushchenko, D. Molochnikov, A. Khokhlov, E. Proshkin, I. Gayaziev, International Scientific-Practical Conference "Agriculture and Food Security: Technology, Innovation, Markets, Human Resources” (FIES 2019), 00018 (2020) doi: 10.1051/bioconf/20201700018

11. A. Glushchenko, A. Khokhlov, D. Molochnikov, A. Husainov, E. Proshkin, I. Gayaziev, IOP Conference Series: Earth and Environmental Science, 403(1), 012099 (2019)

12. A. Glushchenko, A. Khokhlov, D. Molochnikov, I. Salakhutdinov, E. Proshkin, I. Gayaziev, IOP Conference Series: Earth and Environmental Science, 403( 1), 012098 (2019) doi : 10.1088/1755-1315/403/1/012098

13. A. Morozov, G. Fedotov, K. Kundrotas, IOP Conference Series: Materials Science and Engineering, 033058 (2020) doi: 10.1088/1757-899X/709/3/033058

14. A. Abramov, A. Morozov, A. Koshkina, S. Petryakov, J. Nuretdinova, International Conference on Modern Trends in Manufacturing Technologies and Equipment: Mechanical Engineering and Materials Science, 00095 (2019) doi: 10.1051/matecconf/201929800095

15. A. Morozov, G. Fedotov, L. Fedorova, D. Musharapov, L. Khabieva, International Conference on Modern Trends in Manufacturing Technologies and Equipment: Mechanical Engineering and Materials Science, 00117 (2019) doi: 10.1051/matecconf/201929800117.

16. D. M. Maryin, I. R. Salakhutdinov, D. E. Molochnikov, R. N. Musyakimov, I. I. Gayaziev, Vestnik of Kazan State Agrarian University, 14, 4-2(56), 64-68 (2019)

17. A. A. Glushchenko, D. E. Molochnikov, S. A. Yakovlev, I. N. Gayaziev, Vestnik of Kazan State Agrarian University, 3(50), 81-84 (2018)

18. A. V. Morozov, G. D. Fedotov, N. I. Shamukov, Vestnik of Ulyanovsk state agricultural academy, 4(44), 39-44 (2018) doi:10.18286/1816-4501-2018-4-39-44

19. L. Fedorova, S. Fedorov, Y. Ivanova, L. Fomina, A. Morozov, IOP Conference Series: Materials Science and Engineering. Electronic edition, $012384 \quad$ (2020) doi: 10.1016/j.matpr.2019.12.384.

20. A. A. Korotky, E. V. Marchenko, V. V. Ivanov, S. I. Popov, Ju. V. Marchenko, N. S. Dontsov, Model of forming vibration mechanochemical solid lubrication coating on surface of steel rope. XII International Scientific Conference on Agricultural Machinery Industry (INTERAGROMASH 2019): IOP Conference Series: Earth and Environmental Science, 403, 012116 (2019) doi:10.1088/1755-1315/403/1/012116

21. V. V. Ivanov, S. I. Popov, A. V. Kirichek, Qualitative Characteristics of MoS2 SolidLubricant Coating Formed by Vibro-Wave Impact of Free-Moving Indenters. Key Engineering Materials, 736, 18-22 (2017) DOI:10.4028/ www.scientific.net/ KEM.736.18 
22. B. Meskhi, B. Golev, V. Efros, D. Rudoy, A. Olshevskaya, V. Zhurba, Y. Chayka, E3S Web of Conferences, 135, $01083 \quad$ (2019) ITESE-2019 https://doi.org/10.1051/e3sconf/201913501083

23. G. Parkhomenko, I. Bozhko, S. Kambulov, A. Boyko, O. Polushkin, V. Lebedenko, A. Beskopilniy, A. Olshevskaya, E3S Web of Conferences, 175, 09006 (2020) INTERAGROMASH 2020 https://doi.org/10.1051/e3sconf/202017509006 